\title{
Sobre formas e conteúdos: a deficiência como produção histórica
}

\author{
Gustavo Martins Piccolo*
}

Enicéia Gonçalves Mendes**

\begin{abstract}
Resumo
O presente artigo, estruturado metodologicamente mediante processo de revisão literária, objetiva abrir um campo de diálogos e possibilidades no que tange ao entendimento da deficiência pelo prisma da produção social. Principia demarcando a necessidade de pensarmos os fenômenos sociais para além das aparências que lhe apetecem, tendo como segundo ato a contextualização da soberania do saber médico sobre outros conhecimentos como processo ligado umbilicalmente ao fortalecimento do sistema capitalista como tropos societal dominante. Finaliza apresentando o grupo nominado Disability Studies, que interpreta a deficiência como categoria marcada por intensos mecanismos de opressão e segregação histórica, portanto, nada naturais ou eternas, cuja transformação se processa em inequívoca reciprocidade a mutação da própria estrutura social que a circunscreve.
\end{abstract}

Palavras-chave: Educação Especial. Deficiência. Sociologia.

\footnotetext{
* Doutor em Educaçáo Especial pela Universidade Federal de Sáo Carlos (UFSCar). Professor efetivo da rede estadual de Educaçáo de São Paulo.

** Doutora em Psicologia pela Universidade de São Paulo (USP). Professora do departamento de Psicologia e coordenadora da Pós-Graduação em Educação Especial na Universidade Federal de São Carlos (UFSCar).
} 


\section{Palavras Iniciais}

Desconfiai do mais trivial, na aparência singelo.

E examinai, sobretudo, o que parece habitual.

Suplicamos expressamente:

não aceiteis o que é de hábito como coisa natural,

pois em tempo de desordem sangrenta,

de confusáo organizada, de arbitrariedade consciente, de humanidade desumanizada,

nada deve parecer natural,

nada deve parecer impossível de mudar.

Bertold Brecht (1966, p. 18).

O poema de Brecht (1966, p. 18), transcrito como epígrafe deste artigo, nos convida a uma tarefa demasiado escassa nos tempos atuais: duvidar, negar, contrapor, em síntese, pensar. Na suposta sociedade do conhecimento, que a nós parece mais das ilusôes, tudo se desenvolve em uma velocidade alucinante e sob doses avassaladoras de informaçóes. Sequer podemos respirar de tão caótico que se mostra este panorama. Temos de nos apropriar das notícias tal qual de uma laranja no cesto de frutas, inexiste tempo para refletir o composto da mesma, filtrar seu conteúdo. Na lógica capitalista, até em termos de conhecimento o ter se sobrepóe ao ser. Nunca fomos táo ilustrados e pouco pensantes como nos tempos hodiernos, triste paradoxo ao qual somos submetidos.

Talvez, por isso, mas não apenas, o poema de Brecht (1966) desperta acaloradas exaltaçóes, posto representar um grito contra o estado de coisas que nos cerca. Fazme lembrar um dos trechos mais comentados de Marx (1996, p. 271), a citar, "[...] toda ciência seria supérflua se a forma de manifestação e a essência das coisas coincidissem imediatamente". Muda-se a forma, mas o conteúdo de ambos os dizeres guardam ressonâncias e ligaçóes profundas, materializadas em um convite do tipo: pensemos a realidade. Como aponta Lefebvre (1991, p. 218-219):

A aparência, manifestação ou fenômeno, portanto, é apenas um aspecto da coisa, não a coisa inteira. Com relação à essência, o fenômeno é em si mesmo apenas uma abstração, um lado menos rico e menos complexo do que a coisa, um momento abstrato negado pela coisa. A coisa difere da aparência; e, com relaçáo à aparência, a coisa é em si mesma diferença, negação, contradição. Ela não é a aparência, mas sua negação. E, não obstante, 
a aparência está na coisa. A essência não existe fora de sua conexão com o universo, de suas interaçóes com os outros seres.

Colocado estes elementos, nos cabe uma pergunta: Será que a aparência pela qual interpretamos a deficiência corresponde a sua essência? Tal questão foi tornada angular por um grupo acadêmico londrino de deficientes denominado Disability Studies ou teóricos do modelo social da deficiência, os quais, mediante o vértice do criacionismo social, buscam ressignificar sua própria condição como produto de temporalidades históricas específicas e interessadas.

Para os teóricos do modelo social a aparência da deficiência, vista no capitalismo como tragédia e limitação pessoal, também difere de seu verdadeiro significado, emoldurado por fenômenos como a opressão e a discriminação. Entretanto, esse desencontro entre aquilo que o fenômeno é em relaçáo ao que aparenta ser apenas pode ser deslindado na conjunção de um moroso processo analítico de imersão histórico-cultural que aponte os principais condicionantes da gestação de sua epiderme como produção social. Para entender a deficiência é preciso primeiramente se apropriar, em linhas gerais, dos sutis mecanismos pelos quais as sociedades foram nominando e supostamente explicando seus fenômenos universais, desde a explicação de um porquê existencial até a tomada de sentido sobre a lógica que perpassa os corpos disformes, sinteticamente, significa historicizar o aparentemente natural e eterno a fim de demonstrar outros nexos conectivos e possibilidades sequer aventadas ou perdidas pela imposição de um saber hegemônico. Somente em mediação dialética com a sociedade podemos entender o complexo processo que transformou os corpos disformes em corpos deficientes, assim como, a transposição das explicaçôes místicas em reverberaçōes médicas, por fazerem parte da estrutura total que açambarca a sistemática do capital. Referidos elementos nos asseveram a importância em se tracejar um olhar sociológico sobre a deficiência.

\section{Pelas margens da história: elementos para a composição de um quadro analítico}

Falar da deficiência sob um olhar sociológico traz consigo o imperativo premente de secularizaçáo de tal fenômeno, entendendo-o a partir de outras bases que não as míticas e sobrenaturais. A empreitada proposta por esta tarefa 
requer o tracejar sobre os elementos constitutivos da Sociologia, processo da mais relevante seriedade.

Nisbet (1993), em texto seminal, define a Sociologia como uma ciência de núcleo e base moderna. Seu aparecer está relacionado ao contexto engendrado pela Revolução Industrial Inglesa (transformação econômica) e pela Revolução Francesa (transformação política), além do consequente advento de etimologias políticas fincadas nas ideias de progresso, indivíduo, contrato e razão, as quais demarcaram um espaço de cisão para com os laços sociais do Medievo.

Grosso modo, a Sociologia é coetânea ao porvir do racionalismo individualista, da gênese da industrialização/iluminismo e da assunção do Estado como cardeal disciplinador das relaçôes sociais, cujo foco analítico reside na explicação racional do mundo. Seu surgimento liga-se a uma série de eventos e circunstâncias específicas, coincidindo com os derradeiros momentos de desagregação da sociedade feudal e da consolidação da sociedade capitalista. O século XVIII transparece como efetivo marco para a criação da ciência sociológica (apesar da palavra aparecer apenas no século XIX em Comte) devido às transformaçóes políticas, econômicas e culturais dele advindas pela materialização das duas revoluçōes já citadas e também pelo estabelecimento de problemas sociais inéditos para a sociedade de então, tais como: o assalariamento e a alienação do trabalho; a disciplina laboriosa e as novas noçóes de tempo e espaço implantadas pelas máquinas; a questão da urbanização; o desmantelamento da família patriarcal e da moralidade anteriormente estabelecida como dominante; o aparecimento de duas classes contrapostas (burguesia e proletariado), apenas para citar alguns.

Sobre estes elementos a Sociologia finca seu cabedal de relações. Desde então, coube à mesma a tarefa incessante de construir um sistema de pensamento que renunciasse as explicaçóes sobrenaturais dos fenômenos cotidianos em direçâo a uma explicação científica e racional. Engana-se, por conseguinte, quem pensa que a tarefa primeva da Sociologia fosse revolucionária de princípio, muito pelo contrário, sua gênese está relacionada ao acomodar de coisas em uma época absolutamente instável.

Singular, nesse sentido, se apresenta o modelo evolutivo proposto por Auguste Comte, que supostamente proporciona uma compreensão da história do desenvolvimento humano. Comte (1973) sugere que o processo/progresso intelectual humano pode ser dividido em três etapas: teológica, metafísica e positivista, as duas primeiras confundindo-se no espaço e no tempo. Esse 
modelo sugere a passagem, com o avançar da história, de uma interpretação da realidade sob o vértice religioso para outra de origem naturalista, posteriormente superada pela ascensão da forma científica em se compreender o mundo natural e social. A linearidade trifásica apresentada por Comte (1973, p. 247), e pode ser resumida quando afirma:

[...] cada ramo do entendimento da natureza e do humano passa por três fases distintas: estágio teológico ou fictício, estágio metafísico ou abstrato e estágio científico ou positivo. Em outras palavras, o ser humano, por sua natureza evolutiva, emprega sucessivamente em cada um de seus campos de investigação três métodos de filosofar, que, em sua essência, se mostram diferentes e radicalmente opostos. Isto dá origem a três tipos de filosofia ou conceitos gerais de sistema que são mutuamente exclusivos. Náo há como ser positivista e metafísico ao mesmo tempo. Inexiste comunhão entre estas formas de pensar. Ou uma, ou outra. Resta escolher e ceifar as outras opçóes.

Para Oliver (1997), este modelo evolucionista se mostrou útil na compreensão do desenvolvimento da mudança da percepção histórica do desvio, incluindo a homossexualidade, o alcoolismo, a toxicodependência e as doenças mentais, os quais de problemas morais e legais passaram a ser vistas sob mecanismos de controle biomédico. De forma análoga, Albrecht (1976), destaca que uma revisão das práticas médicas ao longo da história, mesmo quando a medicina sequer estava instituída como saber dominante, permite compreender o desvio a partir de três paradigmas que reinaram cada um em determinada época histórica, a citar: a ideia do desvio como pecado, do desvio como crime e, posteriormente, do desvio como doença. Para os referidos autores tal mudança de enfoque pode ser interpretada como uma evolução no pensamento de monta similar a descrita por Comte (1973) do pensamento religioso ao científico.

Referindo-nos especificamente ao fenômeno da deficiência, percebemos que Comte (1973) comete um erro em sua tipologia ao destacar as três vertentes de pensamento como mutuamente exclusivas, posto as formas superadas a serem extirpadas com o adentrar da modernidade. Esta afirmação não resiste ao terreno da empiria. Pfeiffer (2002) destaca que no início do século XX, em Londres, 
a pessoa que apresentava o fenômeno da epilepsia ainda era considerada como se estivesse sendo possuída por forças malignas, contudo, concomitantemente, cria-se um programa estatal que objetivava desenvolver sofisticados tratamentos médicos para a mesma. É o religioso e o mágico convivendo com o científico.

Aliás, não é raro encontrarmos ainda hoje pessoas que explicam a deficiência como resultado de um desígnio divino, isto em plena era de massificação do saber médico. Há contradição nisto? Em Comte sim. Para nós, não, na medida em que acreditamos que a natureza da deficiência apenas pode ser compreendida pela valência de uma arquitetura teórica que leve em conta tanto as mudanças do modo de produção, como também as variaçóes no modo de pensamento e a relação entre ambas. Comte (1973) se concentrou apenas na primeira etapa, esquecendo-se que a transformação social modifica o pensamento, mas não elimina de per si os saberes anteriores. Os mesmos continuam a existir e se propagam tacitamente, ou até por vias oficiais de uma dada sociedade.

Contudo, é inegável, e este é um mérito de Comte (1973), a existência de uma transformação social engendrada pela industrialização que coloca a magia e a religião como formas, quando muito acessórias de explicação dos fenômenos naturais e sociais. Esse processo é bem explicado por Weber (1983), para quem o desenvolvimento do capitalismo se mostra acompanhado de um processo de racionalização do mundo, pelo qual as tradiçóes e o sentimentalismo característicos do medievo são substituídos pelo cálculo e previsibilidade dos acontecimentos. O período que se consolidava com as luzes do século XVIII objetivava clarear as trevas e organizar a sociedade, trazendo a promessa de um novo patamar civilizacional e de um compromisso em dissolver os mitos a fim de substituir a imaginação pelo saber. Desde então, a ciência passou a gozar de suntuoso prestígio, quase inabalável, a qual deveria explicar todos os fenômenos sociais no sentido de resolver seus problemas e as questóes a eles atinentes, objetivando fundamentalmente alavancar maior eficácia da produção industrial. Os homens das cartas são substituídos por peritos, o trabalhador manual qualificado dá espaço à tecnologia das máquinas, o coletivo se fragmenta, individualiza, a moral tradicional é substituída por um sistema judicial abstrato e sistematizada em códigos e leis. Em outras palavras, o ethos moderno efetivamente desencantou o mundo, para nos valermos de uma expressão weberiana.

A transformação conceitual, moral e econômica interfere diretamente 
na composição do entendimento e nas formas de explicação sobre os mais diversos fenômenos sociais. Na aludida cascata axiológica, o corpo que expressa diferenças para além daquelas tidas como variações da própria natureza humana, deixa de ser compreendido a partir de evidências místicas ou de providências da esfera do divino, adentrando ao campo etimológico das incorreçôes biológicas. Este fenômeno é singularmente retratado por Foucault (2000) quando ressalta que com a prevalência da narrativa médica sobre o corpo, novo discurso autorizado pela modernidade, grande parte do que diz respeito ao sobrenatural perdeu força e sentido e o que antes era visto como castigo ou ira dos deuses passou a ser codificado como patologia derivada de determinadas condiçốes clínicas.

Para Foucault (2000), a partir do século XVIII a medicina se estabeleceu como um dos campos do saber em estreita ligação ao poder estatal, intuindo a violenta repressão no que tange ao corpo e, sobretudo, ao que se desviasse de determinado padrão previamente estabelecido. Não é de se estranhar que a mesma pinte todos seus quadros com o esquadro da norma (conceito complexo e de matriz fundamentalmente axiológica), tornada entidade absoluta da busca por seu universal. Apenas com sua dominância sobre outros saberes que presenciamos o nascimento efetivo do deficiente, visto como variação nos padrôes normativos tidos como ideais.

Estabelece-se, assim, uma ordem natural, aquela que coincide com os grupos dominantes, e procura-se demarcar numericamente tudo o que se distingue desta ordem. O surdo é alguém normal subtraído da faculdade de audição. Oposiçóes o definem. O homossexual é, acima de tudo, um não heterossexual. A mulher um não homem. $\mathrm{O}$ negro um não branco. $\mathrm{O}$ cego um não vidente. $\mathrm{O}$ cadeirante um não caminhante. É a ausência que passa a definir aqueles que destoam da suposta norma.

Nesse sentido, toda referência à ordem possível é acompanhada intrinsecamente pela aversão da ordem inversa, ou seja, toda normalidade implica o rechaçar de determinado nível de diferença que pode instaurar uma ordem alternativa. $\mathrm{O}$ diferente do preferível náo é o indiferente, mas o refutável, o detestável, aquele que se deve evitar. Mais do que um definidor a norma guarda consigo um elemento de segregaçáo implícito. Contudo, não podemos perder de vista que a norma jamais apaga a diferença, muito pelo contrário, ela demarca a mesma em um estágio inicial e depois a considera como de menor valia. A deficiência náo é negada pela sociedade, mas reconhecida 
explicitamente para posteriormente ser bombardeada por significações deletérias das mais diversas espécies.

A conjunção desses elementos faz com que Canguilhem (2006) considere a ideia de normalidade como um ponto de corte no processo de inclusão ou exclusão social expresso pelas sociedades capitalistas. O que foge a norma apenas pode ser incluído as margens, uma inclusão por exclusão. Claro que todas as sociedades ao longo de sua história definiram padrōes de inclusão e exclusão, mas em nenhuma delas se observou limites táo rígidos quanto os impostos pelo sistema capitalista e sua máxima do corpo útil e produtivo.

Torna-se nítido que embora não possamos entender a norma por ela própria, sendo necessário recorrermos à análise das relaçóes de produçâo que possibilitam seu aparecimento histórico, tal conceito ocupa um lugar central no desenhar das dinâmicas relacionais e dialógicas expressas contemporaneamente. Normal, norma e normalidade tornaram-se termos cativos desde a massificação do processo de industrializaçáo, e acabam por ter um lugar importante em uma interpretação materialista da deficiência. Assim, mais do que uma preocupação medicinal, deliberar sobre a norma ao campo médico serviu fundamentalmente para demarcar quem podia ou não fazer parte das atividades laboriosas. Este raciocínio encontra guarida em Finkelstein (1993, p. 12), quando destaca que a base de admissão ao trabalho fabril, parte integrante da sociedade moderna, "[...] se dá mediante as medidas corpóreas, ser normal tornou-se um critério dominante e determinante para se conseguir emprego nas sociedades industriais".

Quanto mais avançou o capitalismo e mais elevado se mostrou seu desenvolvimento, mais individualizado se tornou o homem. Esse elevado estado de desenvolvimento trouxe novos problemas de ordem e controle social em sua composição. Dentre este conjunto de problemas, o corpo aparece como portador de novas variáveis, sendo dividido não apenas entre ricos ou pobres, alimentados ou subnutridos, submissos ou indolentes, fortes ou fracos, como observamos em estádios históricos anteriores. Passa a ser também definido entre mais ou menos utilizável, mais ou menos favorável ao investimento rentável, aqueles com perspectivas de maior ou menor grau de sobrevivência e, claro, aqueles que se mostram mais ou menos proveitosos para receber o novo treinamento e disciplina necessária à produção gestada pela máquina. Nas palavras de Oliver (1996, p. 47-48), 
Anteriormente a esta época, a contribuição que o indivíduo fornecia a produção da riqueza social não era computada por cabeça e destacada do grupo. A família, a comunidade, o clâ, enfim, o coletivo produzia e todos eram avaliados pelo conjunto da produção. Sucesso de todos, prejuízo, assim como possíveis sançóes também. Já no capitalismo esta situação se inverte. Agora é o indivíduo que produz. Apenas ele responde por sua produção e as sançóes são aplicadas sobre o corpo do mesmo. Não da família, da comunidade, mas no corpo do indivíduo, cujos insucessos são interpretados como sinônimo de sua falha. Esta nova realidade, conjuntamente a ideia de que os corpos das pessoas com deficiência não se acomodariam aos postulados da sociedade capitalista e do trabalho assalariado acabam por excluí-las deste espaço, assim, passam a ser controladas por aquilo que podemos denominar de economia da exclusão. Este processo de exclusão tornou-se ainda mais acentuado quando do estabelecimento definitivo da ciência médica como braço ideológico do Estado e dos interesses do capital. Tal modelo de intervençáo está enraizado em uma ênfase excessiva no diagnóstico clínico e na visualizaçáo da deficiência como uma natureza trágica e inibidora da humanidade em devir. A deficiência torna-se, sob a alcunha médica, um problema do indivíduo, os quais devem assumir a responsabilidade por sua situação. Eles passam a ser vistos como culpados pelos contínuos fracassos de sua inserção ao corpo social.

Sob os mores modernos é notória a transferência linear do não ajustamento social da pessoa com deficiência a sua fisiologia e corpo desviante, ou seja, direciona-se uma complexa questão social como sendo de única e exclusiva responsabilidade do indivíduo. Quando partimos de tal pressuposto normativo deixamos implícita a ideia de que a pessoa com deficiência apenas se integrará a sociedade quando transformar sua condição orgânica deteriorada e recobrar um suposto estado de normatividade. Logo, retira-se qualquer possibilidade de intervenção que não seja focalizada pelo saber médico, conjunto conceitual denominado por Oliver $(1990,1996)$ de modelo individual da deficiência, cuja teleologia, guiada por um paradigma positivista, procura situar a deficiência 
no plano de uma possível cura, demarcando, assim, um corpo de profissionais específicos para seu trato que, na maioria das vezes, não considera como relevante as vozes dos próprios sujeitos por eles normatizados.

O corpo aludido de saberes gozou de prestígio inabalável até os estertores do século XX, quando em seu último quartil começa a ser criticado de forma visceral, ao menos no que se refere à naturalidade da discriminação sobre o deficiente. Não nos surpreende, portanto, que mesmo em áreas como a Sociologia, epistemologicamente interessada na produção simbólica e material dos conflitos sociais, ecoassem e ainda ecoam vozes quase uníssonas de um discurso composto por falas teoricamente alheias à constituição histórica da deficiência, reiterando a posição tomada por Oliver (1996) de que ao longo de décadas e mais décadas a deficiência foi tratada como um tema pré-sociológico por grande parte das ciências humanas e sociais, as quais a consideravam uma problemática social apenas quando a medicina a havia anteriormente diagnosticada e esquadrinhada. Não se parte de um alicerce carcomido de maneira impune, por conseguinte, as bases sociológicas ao interpretar a deficiência, quando raramente a mesma era considerada, em última instância, se reportavam aos interesses novidadeiros das definiçóes médicas, em outros termos, fazia, se muito, uma sociologia colonizada pelos parâmetros do biológico.

Singular e exemplar na derivação desta perspectiva faz-se o comentário de Abberley (1987), deficiente físico visto como eminente professor londrino de sociologia e figura das mais emblemáticas no campo dos estudos sobre a deficiência, que em escrita autobiográfica destaca que sua percepção sobre a precariedade do saber sociológico na explicaçáo da deficiência se manifestou para ele quando foi convidado no terceiro ano da década de 70 a ministrar uma aula sobre o tema deficiência. No processo preparatório de sua fala constatou que quase nada de efetivamente sociológico existia em relação à temática, esculpida pela interiorizaçâo do olhar médico, sendo assim, acabou por se ver obrigado a falar sobre a deficiência a partir de sua própria condiçáo de deficiente, pois tudo o que poderia ser dito como sociólogo era inadequado se contraposto ao seu conhecimento arquitetado mediante a vivência na carne da experiência da deficiência.

A sociologia do desvio, a psicologia do anormal e a antropologia médica (áreas das ciências sociais que versaram e versam sobre a deficiência de alguma forma), absolutamente, nenhuma delas poderia ser utilizada para os objetivos 
traçados pelo autor. Caso desejasse falar sobre a deficiência sociologicamente era necessário desbravar o campo. Isto porque a ideia que a sociologia tinha da deficiência estava toda amarrada ao referencial médico, coerentemente, quando pretendemos falar sociologicamente sobre a mesma devemos ter em mente que, mais do que receber a descrição do fenômeno, se faz candente concebê-lo, catalisar seu processo de aparecimento histórico. Este novo entendimento de deficiência estaria por nascer. Desde o alicerce, tudo estava ainda para construir.

Posto isso, não se constitui como novidade alguma o fato de histórica e academicamente a deficiência ter sido estudada fundamentalmente sob parâmetros guindados pela ciência médica, ao menos quando nos reportamos aos períodos subsequentes à Idade Moderna e ao estabelecimento do sistema econômico capitalista propriamente dito. Tal processo ocorreu conjuntamente à marginalização da experiência da deficiência manifesta e expressa pelo deficiente, em geral, visto como elo passivo sobre seu próprio caminhar. Para Oliver (1986), a pouca teorização sobre a deficiência em termos acadêmicos está irremediavelmente atrelada a uma grande teoria subjacente a estes elementos, a teoria da deficiência como forma de tragédia pessoal. Esta situação tornava urgente a necessidade de uma tomada de posição, pois no entender de Oliver (1986, p. 15) "[...] se um novo entendimento sobre as questóes raciais e o machismo apenas se deu concomitantemente a tomada de posição efetiva por parte dos negros e mulheres na escrita de suas próprias experiências, fenômeno singular deveria ser tangenciado pelas pessoas com deficiência”.

Partindo deste suposto, Oliver (1996) realiza um extenso estudo sobre as áreas responsáveis pela produção acadêmica que tinham a deficiência como objeto de estudo, em todo o Reino Unido, e acaba por constatar que quase tudo o que adentrava a academia sobre a aludida temática se mostrava como oriundo de lineamentos analíticos médicos e biológicos. No mais, apenas retratos de vida ou autobiografias que se mostravam precárias no sentido de entender a realidade que ali se desdobrava. Como conclusão, enfatizou existir uma necessidade urgente de que outras disciplinas como a Sociologia, Antropologia, História e Pedagogia tomassem para seu escopo analítico a análise da deficiência, na medida em que o perfilhar de um determinado fenômeno sobre outras bases também é um novo entendimento do mesmo. Esta é a finalidade primeira do Disability Studies (que se estabelece em terras londrinas na última década do século XX), a citar, estender projetiva e teleologicamente o campo de abrangência dos estudos que tenham a deficiência como objeto 
analítico, e, por conseguinte, quebrar o grande silêncio que paira nas academias sobre a história da experiência da deficiência.

Para tanto, o primeiro fazer dos fundadores de tal arquitetura intelectiva residiu em fincar as bases de explicação da deficiência sobre um aporte históricomaterial, o qual resvalava diretamente nas dimensóes culturais, políticas e filosóficas da produçáo da mesma. Em tal contexto, os conceitos de Marx se constituíram como plano teórico na explicação da relação entre deficiência e sociedade sob marcos distintos dos utilizados até então. Neste arcabouço teórico, o sistema capitalista foi interpretado como o principal impeditivo ao progresso econômico e cultural das pessoas com deficiência, cuja opressão adquire um caráter objetivo que se estabelece para além das relaçôes dialógicas denegatórias enfrentadas cotidianamente ao se estender para dimensôes não restritas ao terreno da linguagem, do misticismo ou biologia.

Finkelstein (1996) é exemplar na senda desse escopo teórico. A possibilidade de exploração da força de trabalho determina quem é ou não deficiente, incluído ou marginalizado pela sociedade, na medida em que as relaçôes de produção definem a própria condição social de invalidez. No terreno do capital, obcecado pela exploraçáo da força de trabalho, aqueles que são vistos como potencialmente menos exploráveis pelos detentores dos meios de produção, tais como as pessoas com deficiência, em razão de seu suposto desajuste em relação à normalidade instituída pela parafernália industrial, são alijados de tal estrutura. Sem os meios necessários para a manutenção de sua existência, a dependência e o assistencialismo brotam quase que como elementos naturais. Exclui-se uma coletividade para posteriormente incorporálas às margens e justificar a suposta benevolência do sistema produtivo. Este é o grande dilema enfrentado pelas pessoas com deficiência no capitalismo, estar dentro e fora ao mesmo tempo, fazer parte e ser segregado simultaneamente.

Esse fenômeno não deve ser visto como acidental ao capitalismo. Faz parte de sua estrutura, é endêmico tal como suas crises, a exploração do trabalhador e a sua condição miserável, o desmatamento irresponsável e ingovernável da natureza, a necessidade de desemprego e da constituição de um exército industrial de reserva não incorporada à produção a fim de facilitar a manutenção dos baixos salários e das condiçôes degradantes de trabalho. Enfim, todos esses fenômenos, nada naturais, não podem ser vistos, em hipótese alguma, como aberraçōes ou frutos do acaso de determinada época histórica. Assim como a exclusão das pessoas com deficiência das esferas laboriosas, os mesmos são 
inerentes à estrutura do capital, faz parte de sua arquitetura secular e apenas podem ser superados com a superação do próprio sistema.

Extrapolando tal raciocínio a fim de destacar que é o sistema que produz a deficiência da forma como a conhecemos, Abberley (1987) e Barnes (1996) alertam que para além das esferas laboriosas, o capitalismo fabrica diversas formas de deficiência como resultado de seus fatores políticos, sociais e culturais, não havendo nada de inevitável nesta dimensão. Lembrando que a etiologia de várias deficiências está relacionada à má nutrição, extrema pobreza, falta de água encanada e potável, inexistência de saneamento básico, inacessibilidade de remédios e atendimento médico adequado devido à impossibilidade de pagar por esses serviços, recursos e ferramentas, cabendo ainda citar o aumento da criminalidade e guerras, além de condiçôes de trabalho inadequadas. O que há de natural, biológico ou casual nessa condição?

Nada, principalmente quando partimos do pressuposto que as camadas mais favorecidas economicamente não sofrem de qualquer dessas mazelas. Por um simples exercício de especulação indutiva abrolham desse contexto duas aviltantes constataçóes: pela exclusão das atividades laboriosas e a iníqua renda obtida pela imensa maioria das pessoas com deficiência. Ser deficiente tem significado estar alijado dos serviços básicos, a uma existência efetivamente digna, ou em outros termos, significa, invariavelmente, ter uma vida precária. Em síntese, a deficiência tende para a pobreza como a pobreza para a deficiência.

Modular se mostra a assertiva de Hunt (1966, p. 87) ao frisar que "ser pobre é ter metade do caminho andado para tonar-se deficiente". Isso significa que em condiçóes excelentes de existência veremos o desaparecer das deficiências? Claro que não, todavia criaremos um novo significado para tal termo, não deletério como o atual, e garantiremos que nenhuma pessoa se torne deficiente por falta de serviços adequados e de possibilidades que uma sociedade efetivamente democrática deveria garantir para todos seus membros. Essa é a aposta dos Disability Studies ao situar a deficiência como produção social.

Partem, por conseguinte, do pressuposto que o inventariar de dado fenômeno, como a deficiência, mediante sua transformaçáo semântica se configure como parte da transformação do mesmo enquanto matéria efetiva, na medida em que compreendem que as convicçóes sobre o mundo, mesmo que inconscientes, tencionam a maneira pela qual as pessoas se relacionam com determinado fenômeno na sociedade. Ora, se olharmos atentamente para a história da Educação Especial perceberemos que a mesma edifica seu 
corpus teórico a partir de condições prescritas por variantes que não as suas propriamente ditas.

De acordo com Cambaúva (1988), o pensamento liberal e o positivista, ambos formulados e estruturados no decorrer do desenvolvimento das sociedades capitalistas industriais, se constituíram como bases epistemológicas da Educação Especial, que, ao menos inicialmente, transpôs seus conceitos de maneira quase que osmótica. Citado processo deixou profundas marcas que subsistem até hoje no que tange a configuração das relações expressas no campo. Darwin, Lamarck, Itard, Séguin, Binet e Simom, dentre outros, ainda continuam a moldar os tropos semânticos e práticos da Educação Especial. No entender de Kassar (2003), citada incorporação das ciências naturais pelas ciências humanas está diretamente relacionada à maneira pela qual se estruturaram os serviços destinados à população com deficiência pela sociedade, cujo maior exemplo pode ser expresso na excessiva privatização da Educação Especial (vide instituiçôes como Pestalozzi e APAE) em relação à rede pública, mecanismo engendrado com base no suposto da necessidade científica de separar os alunos em normais e anormais. Tal separação se materializou na configuração de um sistema paralelo de ensino que, por muitas vezes, pouco se relacionava com sistema público regular propriamente dito. Este suposto ainda encontra guarida nos tempos atuais por vários segmentos da sociedade. Não se compóe como resquícios de um passado distante e de vaga lembrança. É parte viva da realidade enfrentada pelos sistemas de ensino, e sua origem é medica por excelência. Com isto, náo estamos apontando os dedos para o saber médico. Muito pelo contrário, pois embora sua estrutura gnosiológica venha sendo muito criticada, jamais podemos obnubilar o fato de que os médicos são os verdadeiros artífices no que se refere à abertura da escolarização para pessoas com deficiência. E esse ato foi profundamente revolucionário em princípios do século XIX. O atendimento destinado a Victor de Aveyron por Jean Marc Itard, no entender de Manacorda (1989), revoluciona as bases da pedagogia moderna.

O entendimento fisiológico da deficiência, sua avaliação pautada em testes psicométricos e o atendimento das crianças com deficiência fundado em um conjunto de terapias essencialmente detidas ao campo biológico já foi profundamente inovador. Entretanto, hodiernamente se torna notório que tais supostos também contribuíram para a produçáo de muitos mitos (como a suposta sinonímia entre deficiência e incapacidade, dentre outros) que objetivamos superar quando almejamos a constituição de um ambiente 
verdadeiramente democrático em relação com a deficiência. Daí a força que a ideia de educação inclusiva vem despertando nos mais longínquos recônditos e sua premissa básica na configuração de uma escola que responda e atenda as necessidades apresentadas pelo conjunto dos alunos e por cada um individualmente. No interstício desta transformação, a Educação Especial inevitavelmente terá de se transformar enquanto campo de atuação, uma vez que, além do atendimento educacional especializado, terá a complexa missão de estabelecer apoio e suporte ao sistema regular de ensino de forma cooperativa.

Entretanto, para que a educação inclusiva seja mais que um discurso é preciso que se configure um novo entendimento sobre a deficiência, sendo este mais global e efetivamente comprometido com a emancipação de qualquer ranço segregacionista. Tal caminho pressupóe que superemos a concepção do paradigma médico como a única capaz de explicar a realidade da deficiência. Ela é parte, mas não a totalidade. E é sobre esta hipótese que os Disability Studies conjuram a necessidade de perquirir a deficiência como produção social.

\section{A deficiência como produção social: notas a guisa dos Disability Studies}

Os Disability Studies ou teóricos do modelo social (grupo londrino composto por Mike Oliver, Colin Barnes, Len Barton, Vic Finkelstein e Brendan Gleeson, todos ativistas, com limitaçóes físicas patentes e que içaram a temática da deficiência a uma questão de direitos, valendo-se da contribuição de outras minorias sociais), objetivam chamar a atenção para as tendências de desativação presentes nas estruturas da sociedade moderna e configurar mecanismos que possam gestar políticas, teorias e práticas que confrontem tal situação. A escolha terminológica visa destacar a deficiência como categoria produzida por várias forças: econômicas, políticas, culturais, simbólicas, médicas atitudinais, elemento que impossibilita a explicaçấo da mesma de forma simplista e unilateral.

No entender de Finkelstein (2001), desde a materialização dos princípios do modelo social, nota-se claramente a difusão de uma grande quantidade de outros modelos que se propóem explicativos e tentam estabelecer novos caminhos para políticas públicas sobre a deficiência, assim como oferecer o melhor cabedal explicativo no que tange a explicação da citada condição. Contudo, Santos (2008, p. 503) destaca que efetivamente e de maneira consolidada existem 
[...] duas maneiras diferentes de compreender a deficiência. A primeira afirma que a deficiência é uma manifestação da diversidade humana que demanda adequaçáo social para ampliar a sensibilidade dos ambientes às diversidades corporais. A segunda perspectiva sustenta que a deficiência é uma restrição corporal que necessita de avanços na área da Medicina, da reabilitação e da Genética para oferecer tratamento adequado para a melhoria do bem-estar das pessoas. Já para a compreensão da deficiência como uma desvantagem social e um processo de opressão pelo corpo, os instrumentos analíticos e políticos estão nas ciências sociais e, partindo desse pressuposto, a melhoria das condiçóes de vida da pessoa com deficiência seria possível com as adequaçóes nos ambientes sociais, tornando-os inclusivos.

De acordo com Oliver (1990), a premissa básica do modelo individual consiste na definição do sujeito pelo seu déficit, desde esse ponto de vista, a pessoa com deficiência se reduz a sua deficiência. Os critérios utilizados para se chegar a esta configuração tem como referência a perda completa ou parcial de certos órgãos/funções, assim, a identificação da deficiência, sob o prisma do modelo individual, acaba por se materializar de maneira concomitante ao isolar das características desses órgáos e funçôes por via de comparação com medidas tipificadas como normais e ideais.

Com isso, criam-se critérios que estabelecem para cada órgão ou função comprometida determinados limites da deficiência, por exemplo, capacidade auditiva, intervalos de QI, acuidade visual, dentre outros. Esquadrinha-se o corpo na busca do intervalo ideal de suas referências e medidas para cada órgão ou função particular. Mais do que nunca o homem passa a ser visto como compósito de funçóes isoladas, cujo correto funcionamento necessita da máxima harmonia entre elas. Qualquer desvio afeta o equilíbrio e precisa ser sanado em sua raiz, ou seja, pelo tratamento da partícula que compóe o todo. Seguindo esta linha analítica, Patrícia Brogna (2005, p. 45) destaca que

As práticas históricas do modelo individual da deficiência têm evoluído no sentido de arregimentar significados a corpos distintos, criando infinitas categorias através das quais são definidas as patologias, os sinais e sintomas 
transcritos na matéria corpórea. A visão por trás deste modelo mostra a deficiência como uma questão de "saúde-doença" e inclui a ideia de "sujeito a reparar". Esta dissecção clínica fragmenta a deficiência sob a forma de inúmeras manifestações fisiológicas, impedindo a possibilidade de consolidação de uma imagem coletiva como plataforma de luta, na medida em que todas as forças são destinadas a terapia e reabilitação, responsáveis por enfocar as particularidades do todo.

Em contraposição a esta perspectiva, Oliver (2008) destaca que embora exista uma realidade biológica formatadora de diversas deficiências, não são estas as determinantes no que se refere às contínuas formas de opressão social sofrida por seus sujeitos. Nesse sentido, o que interessa fundamentalmente aos teóricos do modelo social não é a lesão em si, tal qual particulariza o saber médico, mas a opressão materializada sobre a condiçấo da lesão que delimita a deficiência. Essa é a temática que retratam. A deficiência, nesse escopo teórico, deve imperiosamente ser interpretada como uma forma de restrição/opressão social, com isso, objetiva-se rejeitar as categorias de explicação normativa ou qualquer outra forma de construção social divorciada da experiência direta das pessoas com deficiência. $\mathrm{O}$ argumento crucial neste solo histórico é o de que

Todas as pessoas com deficiência experimentam múltiplas maneiras de restriçóes sociais, seja devido à inacessibilidade de alguns ambientes ou de noçôes questionáveis de inteligência e competência social, da inabilidade de a população em geral se comunicar mediante uma linguagem gestual ou pelo uso do Braille, ou ainda pelas atitudes de descrédito e preconceito desferidas contra as pessoas com deficiência. (OLIVER, 1996, p. 44).

O passo fundante rumo a essa discussão foi tracejado quando os Disability Studies edificaram a distinçáo pioneira entre lesão e deficiência, tornada pedra angular do movimento. A lesão é vista como a falta de parte ou da totalidade de um membro, órgão ou sentido não funcional, portanto, refere-se às condições biofísicas do indivíduo, em clara alusão ao modelo individual/médico, enquanto a deficiência trata-se da "desvantagem ou restrição de atividade causada por uma 
organização social contemporânea que não leva em conta as diferenças expressas por pessoas com deficiências, excluindo-as da participação nas atividades sociais" (UPIAS, 1976, p. 14). Sobre esta distinção, se constrói o conceito central pelo qual todas as produçóes posteriores dos Disability Studies irão se reportar, qual seja: "a deficiência é algo imposto, sob a base de nossas lesões, pela maneira como somos desnecessariamente asilados e excluídos da plena participação na sociedade" (UPIAS, 1976, p. 3-4). Exemplar se manifesta a definição prática e concreta da distinção entre lesão e deficiência feita por Morris (1997, p. 25):

Em termos sintéticos podemos definir incapacidade e deficiência de forma bem simples. A incapacidade de andar representa uma lesão, enquanto que a incapacidade de entrar em um edifício, pois a entrada apenas pode ser realizada por um lance de degraus é uma deficiência. Uma incapacidade de falar é uma lesão, mas uma incapacidade de se comunicar porque as ajudas técnicas adequadas não estão disponíveis é uma deficiência. Uma incapacidade de se mover um corpo é uma lesão, mas uma incapacidade para sair da cama porque a ajuda física adequada não está disponível é uma deficiência. A deficiência é produto da exclusão social.

O conceito criado pelo modelo social parte da ideia de que um fato social, a deficiência, apenas poderia ser explicado por outro fato social (uma noção de claro verniz durkheimiano), neste caso, a opressiva sociedade capitalista. Com isso, se objetiva criar um conceito sociológico para a deficiência que pudesse substituir o anterior, de base biológica. Essa forma ontológica de investigação surge em um contexto histórico no qual os acadêmicos negros buscavam criar um novo conceito para raça e explicar a discriminação como produto social e não derivada de qualquer composição biológica.

Tal como o conceito sociológico de raça é diametralmente distinto daquele definido pela biologia, a deficiência conceituada pelo modelo social é radicalmente díspar daquela definida pelo modelo individual. Raça e deficiência, sociologicamente falando, não são conceitos estanques como os derivados da matriz biológica, são conceitos que estão, assim como classe, em contínuo processo de formação. Nunca são permanentes, pois se fortalecem e se alteram com a modificação da sociedade. Aliás, para sociólogos como Guimarães (1995) e Oliver (1990), a consideração da raça e deficiência respectivamente como 
categorias biológicas é um equivoco histórico se partirmos do suposto que a existência nominal, efetiva e eficaz destes termos, apenas se consubstancia no mundo social. Outras intersecçôes sociológicas podem ser feitas sobre a literatura perfilhada pelos Disability Studies.

A distinção entre lesão e deficiência, embora não confessada, se constitui como um claro paralelo em relação aos estudos de gênero, cuja categoria nos oferece subsídios sociológicos para a análise do papel ocupado por homens e mulheres nas esferas cotidianas e não cotidianas. Sinteticamente, tal literatura nos permite a realização de uma analogia fundamental aos Disability Studies, na medida em que, assim como o gênero, ao enfatizar o caráter fundamentalmente social das divisóes baseadas no sexo e destacar que imbricadas às diferenças biológicas existentes entre mulheres e homens estão outras de ordem social e culturalmente construídas. Os estudos sobre a deficiência enfatizam que, com base na lesão, outras diferenças são construídas e atravancam as possibilidades de inserção ao coletivo, acabando por gestar o fenômeno da exclusão.

Destarte, tal como o sexo não explicaria a opressão sofrida pelas mulheres na sociedade, cuja concreticidade deveria ser buscada na estruturação patriarcal da mesma, o corpo com lesão não determinaria o fenômeno sócio-políticocultural da subalternidade experimentada pelos deficientes no capitalismo, o qual apenas poderia ser explicado pela base material de produção de dito sistema em conjunção com o preconceito pessoal e institucional. Explanar a condição de opressão impressa sobre os deficientes em razão de perdas de habilidades provocada pela lesão ou qualquer desorganização biológica era confundir lesão e deficiência, tal como sexo e gênero.

Deficiência é um produto material e simbólico da sociedade, enquanto a lesão pode ser entendida como expressão da biologia humana. Traçando um paralelo com os estudos de gênero, podemos destacar que a deficiência pode ser comparada ao que representa gênero nestes estudos, uma construção social, em contrapartida, lesão seria o equivalente ao sexo, fruto da natureza. Assim como o papel de gênero que cabe a cada sexo é fruto de um longo processo de socialização, a transformação do significado da lesão em deficiência também perfaz uma via estritamente social. Nada há de natural nela, aliás, nada do que é essencialmente humano o é.

Os humanos não são naturais por sua natureza. Não andamos naturalmente sobre as patas traseiras, sendo que enfermidades como pés planos, dores nas costas e as populares hérnias nos testemunham empiricamente e 
de forma carnal que o corpo ainda não se adaptou por completo a estrutura bípede e a postura ereta. Isto prova que até nossas características genéticas e hereditárias são históricas, fruto do domínio do homem sobre a natureza e não do desígnio biológico ou divino. O homem se faz homem por meio de um salto ontológico para fora da natureza, somos o que nos temos feito e, certamente, continuaremos fazendo enquanto existirmos. Tudo o que é natural deve ser situado, contextualizado, uma vez que a naturalização do social representa uma tentativa de inversão da empiria dos fatos como forma de justificar um determinado saber-poder, que tem a função latente de manutenção do status quo e do domínio ideológico exercido sobre as minorias despossuídas quanto aos aportes tidos como ideais.

Citada inversão leva a produção de imagens e ideias que pretendem representar a realidade, formando um imaginário social invertido, um conjunto de representaçóes e conceituaçóes sobre os seres humanos e suas relaçóes, sobre as coisas, sobre o bem e o mal, o justo e o injusto, os bons e os maus costumes, o normal e o desviado. Tomadas como ideias, essas imagens ou imaginário social constituem a ideologia. Naturalizam-se, perdem sua base e arquitetura histórica, não mais se portam como críticas. Sobre esta base são singulares as palavras de Chauí (2000) ao destacar que a funçấo básica deste processo de naturalizaçáo consiste em fazer surgir sob forma de ideias a afirmaçấo de que as coisas são como são porque é natural que assim sejam.

As relaçôes sociais passam, portanto, a ser vistas como naturais, existentes em si e por si, e não como resultados da ação humana. A naturalização é a maneira pela qual as ideias produzem a alienação social, isto é, a sociedade surge como uma força natural estranha e poderosa, que faz com que tudo necessariamente surja como é. Senhores por natureza, escravos por natureza, cidadãos por natureza, proprietários por natureza, assalariados por natureza [acrescentaríamos deficientes por natureza]. (CHAUÍ, 2000, p. 18-19).

Estas situaçóes são colocadas às claras pelo modelo social, que, ao se situar para além do entendimento da deficiência como um problema trágico de ocorrência isolada de alguns indivíduos menos afortunados, para os quais a única resposta apropriada seria o tratamento médico em direção à visualização 
da mesma como uma situação de discriminação institucional coletiva - e para esta a única resposta apropriada é a ação política - inverte radicalmente os vetores que perfilhavam seu entendimento na sociedade (OLIVER, 1990).

Desde então, a categoria deficiência passa a ser vista como um artifício social de exclusão, que penaliza determinadas pessoas por não atenderem as expectativas da média da população em termos de aparência, comportamento ou desempenho econômico. Se é a sociedade que incapacita as pessoas com deficiência, a única forma de estas alterarem tal situação é mediante intensas lutas para transformar o estado atual de forças e assumirem controle sobre suas próprias vidas. $\mathrm{O}$ novo universo gestado pelo modelo social opóe ao discurso colonizador, expresso pelo saber normativo, médico, clínico e reabilitador, uma práxis crítica, sociológica, política, inclusiva e contextualizada. Sob o auspício de uma nova ontologia estabelecida entre deficiência e sociedade, o modelo social, no entender de Giddens (2007), descoloniza o estudo da deficiência das áreas médicas, gestando consequências profundas na formação humana dos deficientes desde entâo, pois como aponta Fanon (1979, p. 26-27),

A descolonização jamais passa despercebida porque atinge o ser, modifica fundamentalmente o ser, transforma espectadores sobrecarregados de inessencialidade em atores privilegiados, colhidos de modo quase grandioso pela roda-viva da história. Introduz no ser um ritmo próprio, transmitido por homens novos, uma nova linguagem, uma nova humanidade. A descolonização é, na verdade, criação de homens novos. Mas esta criação não recebe sua legitimidade de nenhum poder sobrenatural; a 'coisa' colonizada se faz no processo mesmo pelo qual se liberta.

A crítica radical da composição do antigo homem com deficiência eivada por prismas naturalistas gesta, quando interiorizada conscientemente, uma nova forma de pensar.E quando pensamos diferentes já não somos os mesmos. É claro que o surgimento de um novo homem apenas se materializará de fato com o abrolhar de uma nova sociedade. Contudo, e isto é de fundamental importância, apenas quando as pessoas com deficiência forem capazes de indicar o caminho para o qual concorre objetivamente a dialética de seu desenvolvimento é que as mesmas poderão despertar para a consciência do próprio processo, e isto 
implica uma suspensão de tudo o que foi anteriormente dito e feito sobre ser deficiente na sociedade. Somente então a deficiência poderá surgir como categoria derivada da história e seu consequente desmantelar como pressuposto derivado da própria práxis que altera nuclearmente a estrutura social. Este é o desejo inaudito do modelo social.

Por conseguinte, a lógica do modelo social se trata de revoluçấo e não de reforma, ou usando um vocábulo de Finkelstein (2001), uma estratégia de emancipação e não de compensação. O objetivo último do modelo social, de acordo com Barnes (1999, p. 578) é que a criação de um mundo em que

[...] independentemente de deficiência, idade, etnia, sexo, orientaçấo sexual, classe social, status nos postos de trabalho todos possam coexistir como membros iguais na comunidade, sem opressão e discriminação e seguros de que as necessidades de cada um dos indivíduos possam ser acomodadas na íntegra, além disso, as opinióes expressas por estes sujeitos devem ser reconhecidas, respeitadas e valorizadas independentemente da posição que ocupa na sociedade, mesmo porque em tal sociedade a divisão náo mais ditaria os rumos das relaçóes sociais e a própria noção de desigualdade se veria em uma série crise existencial, tendendo ao desaparecimento. Esta será uma sociedade verdadeiramente democrática, caracterizada pela igualdade de oportunidades genuínas e significativas. Continuará a produzir e incrementar suas riquezas, todavia direcionará o vetor das mesmas para o coletivo e não o privado. Esta equidade gerará maiores possibilidades e, por conseguinte, ampliará o foco de liberdade sobre o humano, na medida em que possibilita o efetivo crescimento pela apropriaçáo das diferenças características de cada sujeito e cultura em particular.

Utopia? Depende. Se for lugar algum, certamente que náo. Lugar objetivado aquele que se deseja em um futuro próximo ou distante. Isto sim. Por conseguinte, é fundamental nos despirmos da ideia sobejamente conhecida de que a realização de um ideal revolucionário não pode ser postergado para além da vida daquele que prescreve o mesmo. Não podemos ser tão egoístas 
e querer que tudo se resolva em nosso tempo. O tempo de uma vida humana é dramaticamente escasso, este é o inelutável absoluto da condição humana. Ninguém transcende a morte, entretanto, nem só de presente vive o homem. Acreditar que o mundo será outro e instituído sobre distintas bases após nossa morte, não pode ser visto como credo religioso ou uma espécie de crença na vida após a morte. A história social e a confiança na humanidade nos leva a confiar neste caminho, por conseguinte, cedo ou tarde, continuamos a acreditar no aparecimento de uma nova sociedade que rompa com todo o lineamento da anterior e possa, de fato, denominar-se como democrática.

Mesmo porque, como assevera Oliver (2008), apenas uma sociedade efetivamente democrática guardará um conceito libertário de deficiência, uma vez que na produçáo da própria vida os homens contraem relaçôes determinadas, necessárias e independentes de sua vontade, relaçóes que correspondem a uma determinada etapa do desenvolvimento das forças produtivas materiais. No capitalismo tais relaçóes jamais concretizarão o anseio emancipatório em sua plenitude e possibilidade máxima. Por isso, as pessoas com deficiência náo podem mais se libertarem da classe que a explora e oprime sem que, ao mesmo tempo, liberte toda a sociedade da exploraçáo.

Sociedades de exploração que encontram nas relaçóes burguesas seu último estágio e última forma antagônica do processo social de produção, as quais criam as condições para a própria superação desse antagonismo e permite o encerrar da pré-história da humanidade. Essa outra humanidade finalmente poderá ser marcada como uma sociedade livre, que dá a sensualidade e a sensibilidade seus próprios direitos. No entender de Marcuse (1978, p. 9),

Essas são as características qualitativamente diferentes de uma sociedade livre. Elas pressupóem, como vocês talvez já o tenham visto, uma total transvaloração dos valores, uma nova antropologia. Elas pressupóem um tipo de ser humano que rejeita os princípios performáticos que governam as sociedades estabelecidas; um tipo de ser humano que se livrou da agressividade e da brutalidade que são inerentes à organização da sociedade estabelecida, e da moralidade puritana, hipócrita; um tipo de ser humano que é biologicamente incapaz de lutar nas guerras e criar sofrimento; um tipo de ser humano que tem uma boa consciência de alegria e prazer e que 
trabalha, coletivamente e individualmente, por um ambiente natural e social no qual uma tal existência torne-se possível.

O que é uma sociedade livre e o que podemos fazer em seu terreno histórico? É uma sociedade em que pela primeira vez em nossa vida, efetivamente, poderemos ser livres para pensar a respeito do que iremos fazer - condição ainda não experimentada devido às impossibilidades objetivas de épocas anteriores ao capitalismo e da alienação, pelo qual o presente se estrutura, exprimindo todo seu significado denegatório a humanidade quando suas invençôes técnicas, as quais poderiam libertar o mundo da miséria e do sofrimento, são sistematicamente utilizadas para a criação de novas formas de sofrimento.

Por conseguinte, torna-se fundante a necessidade capital de abolir este sistema de servidão estabelecido e fundar um comprometimento vital com valores qualitativamente diferentes de uma existência humana livre. É preciso ir além da equivocada ideia de que o prazer se encontra resumido ao puro consumo de bens e matérias, o que exige uma educação ampliada para além da adaptaçáo individual, e com um novo sentido que envolva a mente e o corpo, a razão e a imaginação, as necessidades intelectuais e pulsionais. Entretanto, a superação deste individualismo burguês não se dá apenas pelo adotar de um novo estilo de vida.

Sem revoluções não há libertação individual, e sem libertação individual não há libertação da própria sociedade. Esta é a complexa dialética que precisa ser equacionada se objetivamos, efetivamente, transformar a sociedade, processo que inegavelmente relacionado à consecução da tensão habitada entre o subjetivo e o objetivo demarcado em um sistema capitalista de produção. De que maneira fazer isso? Embora o materialismo histórico pareça se constituir no melhor caminho, no sentido de explicar e propor projeçóes sobre a realidade, ainda assim, inexistem receitas ou fáceis soluçôes. Como bem pontua Adorno (2003, p. 133):

Essa pergunta me ultrapassa. Diante da questão 'que fazer' eu na realidade só consigo responder, na maioria dos casos, 'não sei'. Só posso tentar analisar de modo intransigente aquilo que é. Nisso me censuram: já que você exerce a crítica, então é também sua obrigação dizer 
como se deve fazer melhor as coisas. Mas é precisamente isso que eu considero um preconceito burguês. Verificouse inúmeras vezes na história que precisamente obras que perseguiam propósitos puramente teóricos tenham modificado a consciência, e com isso também a realidade social.

Como produto histórico, a experiência da deficiência depende do tipo de sociedade em que estamos inseridos. Como atualmente vivemos sob a égide do capitalismo, Oliver (1990) foca suas argumentaçóes na maneira pela qual este sistema desativa as pessoas com deficiência. Para tanto, parte de um pressuposto de que todas as sociedades existentes até hoje se arquitetam tendo em vista o princípio distributivo da alocação dos bens e serviços, com base no suposto inalienável de que todos são capazes de trabalhar. Todavia, com o avançar dos tempos, a rigidez dos mecanismos de trabalho e as exigências impostas por suas espacialidades e temporalidades específicas, acabaram por criar um segmento da população que ficou impedido de realizar strictu sensu tais atividades, provocando um processo de marginalização aos destituídos destes espaços, vistos como estrangeiros, no sentido de não ter pátria, dentro da própria nação. De definidor da própria humanidade do homem a veículo opressor pela negação de sua possibilidade social, eis o caminho do trabalho com a efetivaçáo do sistema capitalista.

Evidente que tal comentário não pode ser visto como forma de grandezas absolutas. É um aporte em níveis de tendência. Marx (1996) já afirmava de maneira enfática, que o capitalismo também se apropriou dos corpos em dissonância às normas instituídas. Nesse interstício, eram oferecidos os piores salários e postos para os mesmos no intuito único de amplificar o lucro total, processo que longe de amenizar a opressão sofrida por estes sujeitos, torna ainda mais repugnante tal prática.

Ainda sob esses lineamentos, não é escusado lembrar que na década de 20 do século XX, Henry Ford estabeleceu taxas fixas de remuneração para pessoas com deficiência em suas fábricas automotivas. Nas palavras de Ford (apud GLEESON, 1999, p. 27-28),

[...] se mostra totalmente desnecessária a exclusão dos deficientes das fábricas, embora a imensa maioria destas tenham assim procedido há mais de um século. Expulsam 
a torto e direito os deficientes dos ramos de trabalho. Quanta imbecilidade e falta de visão sobre o futuro. Mal imaginam que esta atitude intempestiva e de uma ignorância econômica atroz fomenta fenômenos como a mendicância. Penso totalmente diferente. Os deficientes devem ser empregados nas fábricas, tornando a caridade desnecessária, visto que aqueles que antes pareciam incapazes de ganhar a própria vida e eram retirados das classes produtivas passam novamente a ocupar lugar neste ambiente. Como fazer isso? Simples. Em todo processo produtivo existem funçóes em que o trabalhador não precisa de muita mobilidade para realizar. Algumas delas, aliás, exigem um comportamento estático sob risco de perda da vida ou de membros. Limpeza e desobstrução das máquinas e caldeiras é apenas um destes exemplos. Estas funções podem perfeitamente ser desenvolvidas pelos deficientes. Minhas fábricas já estão a adotar este sistema. Todas possuem uma grande quantidade de deficientes para executar aquelas operaçóes consideradas como de alto risco.Olhem a vantagem deste engenho. Se colabora com a redução desta peste social, que é a mendicância, e ainda se contrata o trabalhador a um preço muito abaixo do que aquele que pagaríamos para um homem sadio. E os deficientes não tem o porque reclamar. De expulsos a empregados com baixos salários é um avanço significativo. Ajudamos a sociedade e nos ajudamos. Pena que não tenha percebido isto antes. Teria feito mais lucro e dado menos dinheiro nas portas das igrejas e nas esquinas das ruas.

Sob este aspecto, o capitalismo não tem preconceito algum quando o assunto reside em objetivar mais lucro e universalizar o processo de retirada da mais valia. Contudo, importa neste momento destacar o quão cruel foi e tem sido dito modus econômico no sentido de englobar a força de trabalho expressa pelas pessoas com deficiência, estejamos falando em sua exclusão destes postos ou em sua inclusão pelas margens. Esta é a anátema dos teóricos vinculados ao modelo social, a citar, o capital é o parteiro da deficiência, o sistema que pari a diferença existencial como limitação e subumanidade.

Baseado neste composto, Oliver (1990, p. 84) reitera que não faz qualquer 
sentido, em termos de luta política, adjetivar a deficiência de sua lesão, pois se recusa

[...] a dividir o grupo em termos de condiçóes médicas, da limitaçáo funcional ou gravidade da deficiência. No meu entender, pessoas com deficiência são definidas em funçấo de três critérios, quais sejam: a) apresentam uma deficiência; b) são oprimidos em virtude de sua deficiência, e c) se identificam como uma pessoa com deficiência, independentemente se intelectual, física ou sensorial. A utilização do termo genérico náo significa, em hipótese alguma, que náo reconheça as diferenças de experiência entre os diversos grupos, mas que parto do princípio de que todos sofrem alguma forma de opressão devido a sua condição.

Coerentemente, a ideia da utilização da deficiência como termo genérico não está em apagar as diferenças, e, sim, em criar um terreno comum profícuo à somatória de forças destas diferenças no que tange a crítica do capitalismo e da consecução de uma teoria rigorosa da deficiência fincada em cânones marxistas.

É evidente que as deficiências guardam diferenças entre si no seio de categorias distintas, e também das mesmas divisóes quanto às necessidades que cada pessoa porventura venha a apresentar. A necessidade de moradia de uma criança deficiente física, filha da classe trabalhadora e vivendo em condiçóes de superpopulação em um conjunto residencial, não são as mesmas daquela criança, também deficiente física, mas filha das elites. De um lado a moradia é quase uma ausência, do outro, uma presença que pode ostentar até certos níveis de luxuosidade. As pessoas não existem simplesmente como deficientes. São deficientes e homens ou mulheres, trabalhadores ou desempregados, negros ou brancos, nativos ou migrantes etc. Portanto, a diferença existe e é inegável.

Este nunca foi um problema e jamais tal relaçáo foi esquecida pelos teóricos do modelo social. O ponto chave, portanto, não é sua existência, mas quem define a diferença como diferença? Como devemos compreender a diferença? De que forma a diferença designa o outro? Que normas são presumidas a partir das quais um grupo é marcado como diferente? Como as fronteiras da diferença são constituídas, mantidas ou dissipadas? Qual a natureza das atribuiçôes que são levadas em conta para definir um grupo como diferente? 
A diferença diferencia lateral ou hierarquicamente? São estas as questôes de fundo a se desenvolver como parte da consecução de uma teoria efetivamente sociológica da deficiência.

\section{Considerações Finais}

O artigo procurou apresentar contribuições para um pensar sociológico da deficiência, entendendo que o mesmo pode se corporificar mediante aprofundamentos futuros em um fator essencial para a transformação da forma pela qual nos relacionamos com a deficiência cotidianamente.

O grupo Disability Studies se nomina perfilhado ao materialismo histórico e estabelece seus condicionantes na suposta cisão estabelecida pelo capitalismo entre produção de bens e a distribuição dos mesmos para o conjunto da sociedade. No entender de Oliver (1990), o capitalismo visa única e exclusivamente o incremento do lucro e o acúmulo de extraçáo da mais valia, pouco se importando na efetiva democratizaçáo do acesso proporcionado por suas conquistas, elemento que seria de fundamental importância para o ofertar de novas possibilidade e oportunidades dirigidas às pessoas com deficiência. Esta contradição é insolúvel e, no entender dos Disability Studies, apenas poderiam se resolver com a transformação do próprio sistema econômico que rege a sociedade. Nesse sentido, há sim uma relaçáo inegável com os escritos marxianos. Todavia, é importante frisar que a principal protoforma constitutiva da sociedade apontada por Marx, a citar, a contradição entre trabalho e capital, é pouco trabalhada pelo grupo. Também não exploram, a contento, a questáo do mercado, que pode ser entendido como pedra de toque na formatação do sistema capitalista nos moldes que conhecemos hodiernamente. Partindo dessas lacunas, muito deve ser desenvolvido no que se refere a uma filiação de fato materialista histórica em seus pormenores. Contudo, mais que uma falha, citado suposto é questão a ser trabalhada de maneira integral.

Ora, inegavelmente um dos maiores desafios do marxismo reside em incorporar novas dimensóes e conflitos surgidos durante a modernidade. As questôes de gênero, raça, etnia e da deficiência, dentre outras, devem fazer parte $\mathrm{da}$ agenda dos novos autores que perfilham da perspectiva marxiana. $\mathrm{O}$ desafio, em nosso, está em criar O Capital para a deficiência assim como Vygotsky fez com a Psicologia. Este é o norte propositivo, cujo produto se encontra em um tempo ainda longínquo. Nesse sentido, é preciso pensar para além de um 
modelo social da deficiência, na medida em que não podemos deixar de lado as contribuições realizadas por outras vertentes, como a médica.

Este equívoco cometido pelos Disability Studies gera certo desconforto epistemológico, pois pode induzir o leitor a interpretar que é o médico que faz da deficiência uma lesão e o saber sociológico que faz da mesma um fenômeno social. Nada mais falso que isso. Tanto a lesão como o caráter social da deficiência possui uma base objetiva de verificação, e isto é esquecido, em alguns momentos, pelos teóricos do modelo social.

Outro vértice que deve ser aberto diz respeito à equiparação da opressáo sofrida pelas pessoas com deficiência em relação a outras minorias a partir do entendimento que as mesmas são sustentadas por apontamentos refutáveis no terreno da prática. Não podemos esquecer que, em algumas deficiências, há sim um efetivo prejuízo que pode ser físico, psíquico ou sensorial, o que não acontece, por exemplo, quando trabalhamos com a temática raça e para a qual inexiste qualquer diferença biológica. Um cego está biologicamente impedido de ter acesso à cultura elaborada por meio da letra impressa, razão pela qual a sociedade cria mecanismos compensatórios como o Braille. Esta é uma questão que carece ser melhor pensada no que se refere à consecução de estudos futuros. Todavia, como movimento tendencial, consideramos deveras salutar a apropriação de outras literaturas de modo a produzir um entendimento efetivamente global da deficiência. Mas esta é uma tarefa que não podemos desenvolver neste momento, assim como, também não desenvolvemos as contribuiçóes nacionais. Por ora, nosso objetivo esteve enraizado na apresentação dos Disability Studies e foi a ele que nos atemos. Esperamos ter contribuído para este processo.

\section{REFERÊNCIAS}

ABBERLEY, Paul. The concept of oppression and the development of a social theory of disability. Disability Handicap and Society, v. 2, n. 1, p. 5-19, 1987.

ADORNO, Theodore. W. Entrevista com Adorno: a filosofia muda o mundo ao manter-se como teoria. Lua Nova, n. 60 p. 131-139, 2003.

ALBRECHT, Gary. The Sociology of physical disability and rehabilitation. Pittsburgh: University of Pittsburgh Press, 1976. 
BARNES, Colin. The social model of disability: myths and misconceptions. Greater Manchester Coalition of Disabled People, United Kingdom, p. 27-33. ago. 1996.

BARNES, Colin. Disability studies: new or not so new directions. Disability \& Society, United Kingdom, v. 14, n. 4, p. 577-580, 1999.

BRECHT, Bertold. Poemas e cançôes. Rio de Janeiro: Civilização Brasileira, 1966.

BROGNA, Paul. ¿¿El derecho a la igualdad? ¿O el derecho a la diferencia? El Cotidiano, Azcapotzalco,v. 21, n. 34, p. 43-55, nov./dez. 2005. In: <http:// redalyc2.uaemex.mx/pdf/325/32513407.pdf>. Acesso em: 10 mar. 2012.

CAMBAÚVA, Lenita. Análise das bases teórico-metodológicas da educação especial. 1988. Dissertaçáo (Mestrado em Educaçáo) - Pontifícia Universidade Católica de São Paulo, São Paulo, 1988.

CANGUILHEM, Georges. O normal e o patológico. Tradução de Maria Teresa Carvalho Barrocas. Rio de Janeiro: Forense Universitária, 2006.

CHAUÍ, Marilena. Convite à filosofia. 11. ed. São Paulo: Ática, 2000.

COMTE, Auguste. Curso de filosofia positiva. São Paulo: Abril Cultural, 1973.

FANON, Frantz. Os condenados da terra. Rio de Janeiro: Civilizaçăo Brasileira, 1979.

FINKELSTEIN, Vic. The commonality of disability. Sage: Open University Press, 1993.

FINKELSTEIN, Vic. The disability movement has run out of steam. Disability Now, United Kingdom, feb. 1996.

FINKELSTEIN, Vic. A Personal Journey into Disability Politics. Independent Living Institute, Farsta, 2001. Disponível em: <http://www. independentliving.org/docs3/finkelstein 01a.html>. Acesso em: 12 out. 2011.

FOUCAULT, Michel. As palavras e as coisas. São Paulo: Martins Fontes, 2000.

GIDDENS, Athonny. Sociology. 6. ed. Cambridige: Polity Press, 2007. 
GLEESON, Brendan. Geographies of Disability. London: Routledge, 1999.

GUIMARÃES, Antônio S. Racismo a anti-racismo no Brasil. Novos Estudos, São Paulo, n. 43, 1995.

HUNT, Paul (Org.). Stigma: the experience of disability. London: Geoffrey Chapman, 1966.

KASSAR, Mônica. Políticas educacionais e sujeitos: contribuiçôes para desenhos de pesquisas em Educação Especial. Revista Perspectiva. Florianópolis, SC, v. 21, n. 2, p. 413-430, jul./dez. 2003.

LEFEBVRE, Henry. Lógica formal, lógica dialética. 5. ed. Rio de Janeiro: Civilização Brasileira, 1991.

MANACORDA, Mário. A. História da educação: da antiguidade aos nossos dias. São Paulo: Cortez, 1989.

MARCUSE, Herbert. Razão e revolução: Hegel e o advento da teoria social. Tradução de Marilia Barroso. 4. ed. Rio de Janeiro: Paz e Terra, 1978.

MARX, Karl. O Capital: crítica da economia política. São Paulo: Nova Cultural, 1996. v. 1.

MORRIS, Jenny. Introducción. In: MORRIS, Jenny (Ed.). Encuentros con desconocidas: feminismo y discapacidad. Madrid: Narcea, 1997.

NISBET, Robert. Las dos revoluciones. In: NISBET, Robert. La formacion del pensamiento sociologico. Buenos Aires: Amorrutu, 2003.

OLIVER, Mike. Social policy and disability: some theoretical issues. Disability, Handicap \& Society, Oxfordshire, v. 1, p. 5-17, 1986.

OLIVER, Mike. The politics of disablement. Basingstoke: Macmillan, 1990.

OLIVER, Mike. Understanding disability: from theory to practice.

Basingstoke: Macmillan, 1996.

OLIVER, Mike. Changing the social relations of research production.

Disability, Handicap \& Society, Oxfordshire, v. 7, p.101-115, 1997.

OLIVER, Mike. Políticas sociales y discapacidad: algunas consideraciones teóricas. In: BARTON, Len (Org.). Superar las barreras de a Discapacidad: 18 años de "Disability and Society". Espańa: Morata, 2008. p. 19-33. 
PFEIFFER, David. The philosophical foundations of disability studies. Disability Studies Quarterly, v. 22, n. 2, p. 3-23, 2002.

SANTOS, Wellington, R. Pessoas com deficiência: nossa maior minoria. Physis, Rio de Janeiro, v. 18, n. 3, 2008.

UPIAS. Fundamental Principles of Disability Union of the Physically Impaired Against Segregation. United Kingdom, 1976.

WEBER, Max. A ética protestante e o espirito do capitalismo. Traduçáo de Maria Irene de Q. F. Szmrecsanyi. 3 ed. São Paulo: Pioneira, 1983. 


\section{About forms and contents: disability as historical production}

\section{Abstract}

The purpose of this article is to use a bibliographic review to open a field of dialog and possibilities regarding the understanding of disability through the prism of social production. It begins by demarcating the need to think about social phenomena beyond their appearances. It then contextualizes the sovereignty of medical knowledge over other knowledge as a process intimately linked to the strengthening of the capitalist system as dominant societal tropes. It concludes by presenting what is known as Disability Studies, which interprets disability as a category marked by intense mechanisms of oppression and historical segregation, therefore, as nothing natural or eternal, whose transformation is processed in unequivocal reciprocity to mutation of the very social structure that circumscribes it.

Keywords: Special Education. Disability. Sociology.

\section{Gustavo Martins Piccolo}

E-mail: gupiccolo@yahoo.com.br

\section{Enicéia Gonçalves Mendes}

E-mail: egmendes@ufscar.br

\section{Acerca de formas y contenidos: la discapacidad como una producción histórica}

\section{Resumen}

Este artículo se estructura a partir de un proceso de revisión de la literatura, y tiene como objetivo establecer un diálogo y un campo de posibilidades en relación a la comprensión de la discapacidad a través del prisma de la producción social. Primeramente se apunta la necesidad de pensar los fenómenos sociales más allá de las apariencias. Seguidamente se realiza la contextualización de la soberanía del conocimiento médico como un proceso estrechamente ligado al fortalecimiento del sistema capitalista. Finaliza presentando el grupo Disability Studies, que piensa la discapacidad como una categoría marcada por intensos mecanismos de opresión y segregación, hechos históricos y, por lo tanto, no hay nada de natural en lo eterno, en que la transformación está circunscripta no contexto de la actual estructura social.

Palabras claves: Educación Especial.

Discapacidad. Sociologia.

Recebido em: 27/1/2012

Versáo final recebida em: 19/11/2012

Aprovada em: 21/11/2012 